\title{
Objective evaluation for treat to target in Crohn's disease
}

\author{
Kento Takenaka $^{1,2}$ (1) Yoshio Kitazume $^{3} \cdot$ Toshimitsu Fujii $^{1} \cdot$ Kiichiro Tsuchiya $^{1} \cdot$ \\ Mamoru Watanabe $^{1,4} \cdot$ Kazuo Ohtsuka $^{5}$
}

Received: 27 January 2020/Accepted: 16 February 2020/Published online: 4 March 2020

(C) The Author(s) 2020

\begin{abstract}
Background Crohn's disease (CD) is a chronic and destructive bowel disease; continued disease activity can lead to penetrating complications. With the recent advent of effective medications, the importance of using a treat-totarget approach to guide therapy is becoming important. Methods In this review, we reviewed the previous evidence for evaluating CD lesions.

Results We describe ileocolonoscopy's role in assessing disease activity, as well as recent progress in modalities, such as balloon-assisted endoscopy, capsule endoscopy, magnetic resonance enterography, computed tomography enterography, and ultrasonography. Advances in modalities have changed $\mathrm{CD}$ assessment, with small-bowel involvement becoming more important.

Conclusions Proper optimization is necessary in clinical practice.
\end{abstract}

Kento Takenaka

ktakenaka.gast@tmd.ac.jp

1 Department of Gastroenterology and Hepatology, Tokyo Medical and Dental University, 1-5-45 Yushima, Bunkyo-ku, Tokyo 113-8519, Japan

2 Department of Collaborative Medicine for Gastroenterology and Hepatology, Tokyo Medical and Dental University, Tokyo, Japan

3 Department of Radiology, Tokyo Medical and Dental University, Tokyo, Japan

4 TMDU Advanced Research Institute, Tokyo Medical and Dental University, Tokyo, Japan

5 Endoscopic Unit, Tokyo Medical and Dental University Hospital, Tokyo, Japan
Keywords Inflammatory bowel disease $\cdot$ Mucosal healing · Endoscopy · Enterography · Ultrasonography

\section{Introduction}

Crohn's disease (CD) is a chronic and destructive bowel disease, which, if left untreated, leads to penetrating complications [1-4]. Traditionally, treatment goals centered solely on symptom control, before it was recognized that many patients with $\mathrm{CD}$ have continued disease activity without clinical manifestations. Treatment targets have, therefore, shifted from simply relieving clinical symptoms [5] to developing objective target endpoints [6]. Appropriate therapy for a disease is based on its precise assessment. With the recent advent of effective medications, the importance of using a treat-to-target approach to guide therapy is becoming evident [8]. Mucosal healing is considered an important target of inflammatory bowel disease (IBD) therapy [9]. Since $75 \%$ of patients with CD have small bowel (SB) lesions, SB evaluation is also important [10], as the assessment of transmural inflammation and extra intestinal complications.

In this review, we aim to describe ileocolonoscopy's role in assessing disease activity, as well as recent progress in modalities, such as balloon-assisted endoscopy (BAE), capsule endoscopy (CE), magnetic resonance enterography (MRE), computed tomography enterography (CTE), and ultrasonography (US), which enable direct assessment of lesions deep within the SB (Fig. 1). SB follow-through is still used for evaluating SB lesion in the real world. It is, however, less sensitive and inferior to other SB imaging modalities described above [11]; and we do not state SBFT in this review. In addition, this review will not focus on diagnosis and neoplastic surveillance because those are 


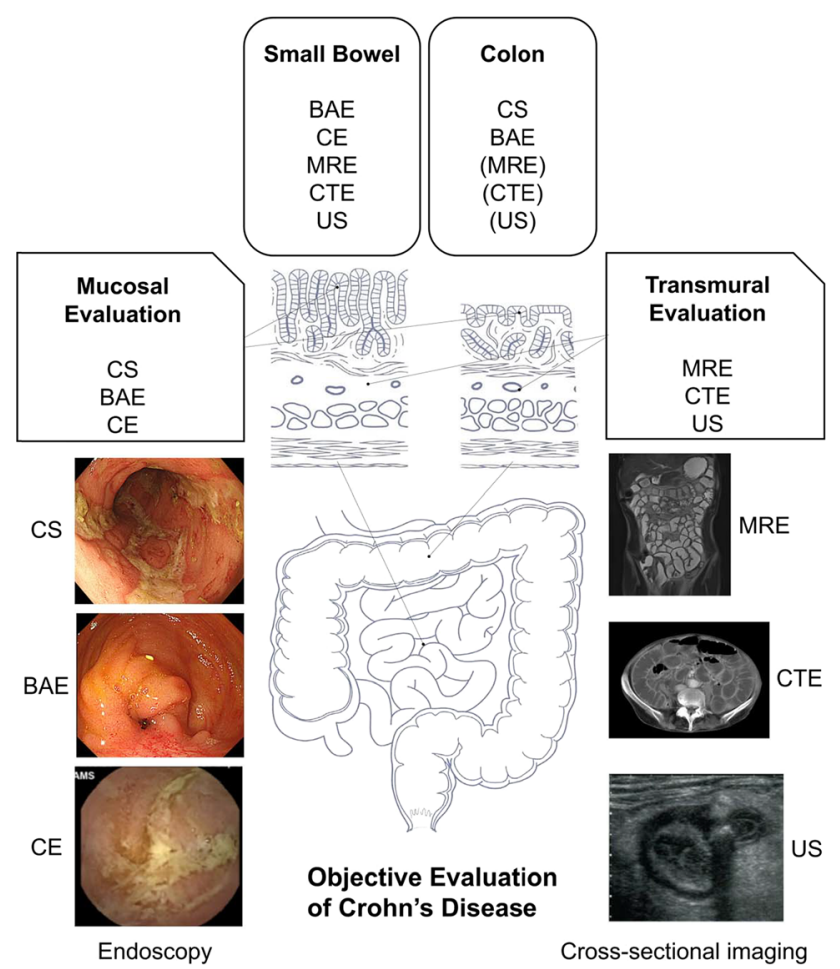

Fig. 1 Examinations for evaluation of Crohn's disease

discussed in detail elsewhere in this issue. Endoscopy and cross-sectional imaging in $\mathrm{CD}$ play major roles in predicting disease severity and achieving tailored patient management. Recent practices and future advances in evaluation for patients with $\mathrm{CD}$ are reviewed.

\section{Ileocolonoscopy}

Mucosal healing is now considered a treatment goal in both clinical trials and clinical practice [5]. In numerous clinical trials, mucosal healing has been associated with improved outcomes in $\mathrm{CD}$, including sustained clinical remission, steroid-free remission, reduced rates of surgery, and fewer hospitalizations [9, 12-17]. Patients with CD with mucosal healing have a reduced risk of penetrating complications and less need for surgery [18]. A study by Bouguen et al. found that a treat-to-target approach in clinical practice, involving endoscopic assessment of disease activity combined with adjustments to medical therapy, increased the likelihood of a better prognosis [19].

The Crohn's Disease Endoscopic Index of Severity scoring system and the Simple Endoscopic Score for CD (SES-CD) have been used frequently in clinical trials to standardize the definition of mucosal healing [20, 21]. The main limitation of these scores is that their operating characteristics, in terms of validation, responsiveness, and reliability to assess inflammation and predict outcome in $\mathrm{CD}$, are still unclear [22]. There is no validated optimal cut-off score, and disease severity has likewise quantification not yet been standardized. It is important to note that there is no validated definition of mucosal healing to date, and currently, no scoring system is used in general clinical practice. The International Organization for the Study of IBD (IOIBD) has provided a consensus definition of mucosal healing in $\mathrm{CD}$ as the complete resolution of visible ulcers [23]. The Selecting Therapeutic Targets in Inflammatory Bowel Disease program recommended that the absence of ulceration is used as an endoscopic target and that disease activity should be reassessed 6 to 9 months after treatment [5].

Strictures are a common and important CD complication. Indeed, $70 \%$ to $80 \%$ of patients with $\mathrm{CD}$ require surgery within 20 years of diagnosis, mostly due to stricture disease [24]. Endoscopy is useful in both diagnosing and treating strictures. For diagnosis, endoscopy can help differentiate between inflammatory and fibrotic strictures and guide therapeutic management. Endoscopic balloon dilation (EBD) is a less invasive therapeutic alternative to surgery for patients with strictures. Initial response rates of $65 \%$ to $97 \%$ have been reported for EBD in combined studies of both anastomotic and primary strictures [25]. A recent meta-analysis of studies evaluating EBD has reported rates of post-dilation failure, requiring surgical intervention in $18 \%$ of anastomotic strictures compared with $29 \%$ of primary strictures [26]. The combined major adverse event rate was only $4 \%$, and the rate of perforation was only $3 \%$. A stricture length of $<4 \mathrm{~cm}$ was associated with a surgery-free response [27].

Endoscopic assessment of postoperative CD recurrence is also an indispensable part of optimized management of patients with $\mathrm{CD}$. Ileocolonoscopy plays a key role in evaluating for and determining the severity of, postoperative CD recurrence. Endoscopic findings of disease recurrence occur in most patients within a year of a surgical resection and frequently occur before clinical symptoms arise [28, 29]. The Rutgeerts score, a widely used schema to grade recurrence at ileocolonic anastomoses, can predict progression to clinical symptoms [30]. An IOIBD expert consensus panel recommended defining postoperative remission as a Rutgeerts score of $\leq \mathrm{i} 1$ [5]. As such, endoscopic evaluation is recommended at 6 to 12 months postoperatively to assess endoscopic recurrence, with medical therapy adjustment $[31,32]$. Again, the score lacks formal validation, and it is unclear which level of ileal inflammation constitutes clinically meaningful recurrence.

\section{Balloon-assisted endoscopy}

Ileocolonoscopy is generally used to assess endoscopic lesions, but it can only assess the terminal ileum and might underestimate true SB lesions [33]. Novel BAE techniques 
have further increased the detection of SB mucosal lesions $[34,35]$ as well as allowing intubation for tissue acquisition and even therapeutic interventions [36]. Most studies have been reported retrospectively, and routine BAE's feasibility and diagnostic utility in clinical practice for $\mathrm{CD}$ have yet to be established [37, 38]. However, several studies on BAE's utility for evaluating SB CD, and endoscopic treatment for strictures, have been reported in a prospective series from Japan [39-42].

To assess inflammatory activity, a retrograde insertion is recommended because most $\mathrm{CD}$ lesions are located in the ileum; meanwhile, anterograde insertion should be performed for unknown upper locations [39]. SES-CD is a validated endoscopic scoring system for $\mathrm{CD}$, but it is used for ileocolonoscopy, and SB lesions are not included [21]. Modified SES-CD has now been proposed, dividing the SB into three segments: terminal ileum, proximal ileum, and jejunum [40]. We have reported that BAE detected active lesions not only in the terminal ileal segment but also in the proximal ileal segment at a higher rate [39]. In addition, BAE findings have shown a poor correlation between endoscopic lesions and the Crohn's Disease Activity Index (CDAI)/C-reactive protein (CRP). One prospective study found SB ulcerative disease in $45 \%$ of patients with clinical and biological remission, and lesions were independent risk factors for poor prognoses (relapse, hospitalization, surgery) [41]. Due to CD-related complications, BAE insertion is sometimes difficult. Takabayashi et al. reported a novel, ultrathin, single-balloon enteroscope showed adequate insertability and safety for outpatient BAE performance [43].

BAE can precisely evaluate SB strictures and also perform EBD for symptomatic patients [42, 44]. For smallbowel strictures not within reach of traditional endoscopy, deep enteroscopy can allow for evaluation and dilation in a technique similar to that used for colonic or ileocolonic strictures. A recent nationwide prospective study showed that procedure failure occurred in only $6.3 \%$ of cases, and short-term symptomatic improvement was achieved in $69.5 \%$. In addition, adverse events occurred in 5\%, and all of these improved with conservative treatment.[42]. However, this technique can be more technically complicated, given the limited size and angulation of the small bowel, and the insertion route must be determined by imaging [45].

Safety is another key for optimizing BAE in CD. The perforation rate, both with diagnostic and therapeutic BAE in $\mathrm{CD}$, was similar to that observed when used for other indications [46]. Another meta-analysis showed diagnostic $\mathrm{BAE}$ in $\mathrm{CD}$ has a similar perforation rate as diagnostic BAE for all indications [47]. However, endoscopy's invasiveness should not be ignored, and BAE has a high rate of incomplete enteroscopy [48]. Careful patient selection is a key factor in optimizing BAE use in CD.

\section{Capsule endoscopy}

CE noninvasively visualizes the entire SB mucosa [49], and several studies have evaluated SB CE's role in detecting known and/or suspected CD.

In suspected $\mathrm{CD}$ with previously negative ileocolonoscopy and/or radiologic workup results, SB CE's diagnostic yield ranges from 26 to $71 \%$ [50, 51]. These studies had reported a higher yield in the setting of a clinical suspicion of $\mathrm{CD}$, in addition to objective laboratory findings, such as anemia and elevated inflammatory markers. Despite the potentially high yield, many abnormalities found on $\mathrm{CE}$ are not specific to $\mathrm{CD}$; thus, criteria for the diagnosis of $\mathrm{CD}$ by $\mathrm{SB} \mathrm{CE}$ remains an area of uncertainty [52, 53].

CE in established CD has high detection rates of smallbowel inflammation [54, 55] and is sensitive for detecting lesions at previously unrecognized locations [56]. A metaanalysis has shown that capsule endoscopy is superior to barium studies, CTE, push enteroscopy, and ileocolonoscopy for detecting recurrent small-bowel CD [57]. In another meta-analysis, however, capsule endoscopy was found to have a diagnostic yield that was similar to MRE and small-intestine contrast US [58]. A recent prospective study showed video CE predicts both short-term and longterm risk of disease exacerbation [59].

Despite the potential diagnostic yield, two notable limitations of small-bowel capsule endoscopy have reduced its use in diagnosing and managing CD: the inability to obtain tissue for histologic evaluation and the risk of capsule retention. Rates of capsule retention requiring intervention have varied between studies and have been reported in $1 \%$ to $13 \%$ of patients with known CD [60, 61]. Cross-sectional imaging could help predict such strictures [62]; however, investigation with a patency capsule is recommended before CE.

\section{Magnetic resonance enterography}

The joint European Crohn's and Colitis Organization (ECCO)/European Society of Gastrointestinal and Abdominal Radiology (ESGAR) guidelines mentioned that MRE is an important cross-sectional imaging technique for assessing SB CD [63]. Transmural healing has been associated with improved long-term outcomes in CD [64]. MRE's advantage is that it can acquire bowel images at multiple time-points and cinematic images to evaluate peristalsis. MRE provides both anatomic and functional information; because of higher resolution and more rapid 
image acquisition, it has now become the modality of choice for SB CD imaging [65, 66].

Adequate distension of the small intestine is also important for high-quality images and diagnostic accuracy [67]. Recently, several consensus statements for the optimal MRE technique in CD have been released [68, 69]. Several signs of inflammation and intestinal damage during evaluation for CD can be assessed, such as abscess, comb sign, fat edema, fistula, lymph node enhancement, reduced motility, mucosal lesions, strictures, and wall enhancement. A meta-analysis has shown that the most important signs of inflammation are wall thickness and wall T2-hyperintensity [70]. An early study on diffusion-weighted magnetic resonance imaging reported that it was comparable to gadolinium enhancement for detecting inflammation in CD [71]. MRE can provide a quantitative assessment of small-bowel motility, showing the motility of inflamed bowel segments decreases compared with noninflamed segments. There are also advantages to using cine MRE over static imaging to investigate intestinal damage, such as adhesions, fistulas, and strictures [72].

Several disease activity scores have been proposed [73-78], including the Magnetic Resonance Index of Activity (MaRIA) [73], London [74], and Clermont [75] systems. The MaRIA, which scores wall thickness, relative contrast enhancement, mural edema, and ulcers in various segments of the gastrointestinal tract, is the most widely used [73]. The global MaRIA score was calculated as the sum of the MaRIA in the ileum and five colorectal segments: ascending colon, transverse colon, descending colon, sigmoid, and rectum. However, SB allocation is relatively small; thus, applied MaRIA can been used by dividing the small intestine into three segments: terminal ileum, proximal ileum, and jejunum. Applied MaRIA is well correlated with BAE findings [40]. The Lémann index has been proposed for intestinal damage assessment [79]. Scoring systems are often complicated and mainly used for clinical trials; however, several simple MRE scoring systems have been proposed for use in clinical practice [77, 78].

MRE could detect SB involvement and predict prognoses in patients with negative inflammation on ileocolonoscopy [80]. A recent meta-analysis has shown that the pooled sensitivity and specificity for MRE in detecting active SB CD were $87.9 \%$ and $81.2 \%$, respectively [81]. The area under the curve (AUC) of MRE for detecting fistulas, stenoses, and abscesses was 0.936, 0.931, and 0.996, respectively. We had compared MRE and BAE findings and found that MRE was highly accurate for inflammatory SB activity, both in cross-sectional evaluation and prognostic prediction [39, 41]. Moreover, BAE and MRE showed no significant differences in terms of the AUC for predicting clinical relapse $(p=0.26)$, hospitalization $(p=0.96)$, and surgery $(p=0.89)$. For intestinal damage, however, MRE showed less sensitivity for strictures than enteroscopy [39]. Magnetic resonancenegative strictures did increase the risks for surgery compared with the patients with no SB strictures [82].

\section{Computed tomography enterography}

Patients with CD were frequently evaluated with CTE during acute exacerbations [83]. CTE can be used as a complementary approach to identify mural healing or inflammation not detected by other methods [84]. One prospective study reported that CTE appears to be effective for monitoring activity in patients with SB CD, including patients with strictures that cannot be traversed by conventional endoscopy [85]. Another advantage is that CTE has better spatial resolution and requires a significantly shorter acquisition time, whereas MRE is currently less accessible and significantly more costly [86]. CTE provides specific, measurable parameters in evaluating the response to therapy in CD patients as well [87].

Although the anatomical resolution with CTE is excellent, routine monitoring with CTE should be weighed against the potential risks associated with radiation exposure [88]. Reducing radiation exposure as much as possible is recommended.

\section{Ultrasonography}

International experts recommend bowel US as a tool for evaluating $\mathrm{CD}$ lesions in terms of complications, postoperative recurrence, and response to medical therapy [89]. It avoids radiation exposure and is, furthermore, available at bedside and associated with low costs. US techniques include Doppler US [56], with contrast agents such as contrast-enhanced US [90] and small-intestine contrast US [91, 92], and ultrasound elasticity imaging [93].

Recent interesting studies have included transmural healing under therapy as a treatment endpoint and have associated it with long-term good outcomes [94, 95]. A past study has shown an almost perfect agreement for abscesses, as well as substantial agreement for maximum bowel wall thickness, stricture, and penetrating disease [96]. Castiglione et al. [97] were among the first to define and highlight the concept of transmural healing as a bowel wall thickness of $<3 \mathrm{~mm}$, assessed by bowel US. An elegant multicenter study conducted recently found that the response to therapy was associated with statistically significant reductions in bowel wall thickening or stratification, decreased fibrofatty proliferation, and increased signals on color Doppler ultrasound [98]. US is widely available and noninvasive; however, its accuracy depends on the examiner and is low in the proximal to terminal 
ileum region [99]. An international multicenter study reported that most US parameters used in CD showed moderate/substantial agreement [100]. Further studies will clarify the proper use of such non-ionizing radiation techniques.

The ultrasonographic subfield of multispectral optoacoustic tomography (MSOT), which is a new technique, was tested recently for the first time in 108 patients with $\mathrm{CD}$ to evaluate intestinal inflammation noninvasively [101]. Performing noninvasive transabdominal MSOT on patients with active $\mathrm{CD}$, as well as those in remission, demonstrated that MSOT-based assessment of total hemoglobin within the intestinal wall had an excellent correlation with the endoscopic degree of inflammation. These preliminary data suggest that MSOT-based assessment of hemoglobin levels in the intestinal wall might help assess mucosal healing in patients with $\mathrm{CD}$.

\section{Noninvasive biomarkers to assess Crohn's disease lesions}

CRP is the only blood marker used routinely in the clinic [102]. Although CRP normalization is associated with therapeutic response, CRP levels were shown to correlate only modestly with endoscopic disease activity $[103,104]$. Up to $25 \%$ of patients with demonstrable endoscopic activity did not have increased CRP levels [105].

Fecal calprotectin (fC) represents an attractive biomarker, found in the stool of patients with CD since it has the advantage of increased specificity for inflammatory processes in the gut. However, it does not represent an IBDspecific fecal biomarker and is also elevated during other inflammatory or infectious processes. $\mathrm{fC}$ is $87 \%$ accurate for detecting endoscopically active inflammation [106]. The fC levels correlated best with colonic or ileocolonic disease, but to a markedly lesser extent with ileal disease [107]. However, a recent prospective study has reported fC showed a significant correlation with the intestinal inflammation evaluated with BAE, even in patients with the only small intestinal disease [108]. The fecal immunochemical test (FIT) is another fecal biomarker, and both FIT and fC were correlated with the mucosal status of CD [109].

A recently conducted, randomized controlled trial evaluated the therapeutic strategy of escalating therapy by tight control, based upon failure criteria defined by CRP, fC, CDAI, and prednisone use (TC group), compared with clinical management relying on only CDAI and prednisone use (CM group). The primary endpoint of mucosal healing at week 48 was met by $46 \%$ (48/122) in the TC versus $30 \%$ (37/ $122)$ in the CM group $(p=0.010)$. These results might affect future therapeutic algorithms in $\mathrm{CD}$, including biomarkerbased therapeutic decisions, and they underscore the ability of CRP and fC elevation to reflect active disease in CD [110].

\section{Discussion}

There is strong evidence in favor of mucosal healing for improving clinical outcomes; however, several questions remain unanswered. In $\mathrm{CD}$, mucosal healing, as defined by white-light colonoscopy, might not always reflect healing of all tissue layers, and endoscopy does not address transmural healing [7]. This leads to the question of whether more comprehensive targets should be sought. Crosssectional imaging can acquire information about the deep layers of the bowel wall and extraluminal complications, such as abscesses and fistulas. Furthermore, colonoscopy's ability to evaluate the extent and severity of the disease completely can be limited, particularly in the setting of more proximal SB disease. SB lesions have been observed in $70 \%$ of patients, and clinical or biochemical markers of disease activity infrequently correlate with SB inflammation [111]. Additionally, SB disease is difficult to cure with medical treatment [112], and deep SB involvement is associated with poor prognoses [113]. Evaluating SB CD will be important in the future.

Taken together, the role of objective evaluation in $\mathrm{CD}$ is rapidly evolving. All examination modalities have pros and cons (Table 1). Ileocolonoscopy is an important tool for evaluating mucosal healing; however, $\mathrm{SB}$ assessment is limited. BAE enables detailed SB mucosal evaluation, histological assessment, and endoscopic therapy, but its low accessibility and high invasiveness could be a limitation for general use. CE is less invasive, yet retention is still a critical limitation, and the clinical importance of minimal lesions is uncertain. MRE is a widely accepted examination technique and has good monitoring for $\mathrm{SB} C D$, but inspectable facilities are still limited, and assessment of SB strictures shows low sensitivity. CTE has good accessibility and high spatial resolution; however, radiation exposure is a major limitation in monitoring CD. US is noninvasive and repeated assessment is suitable for clinical use, but its accuracy depends on the examiner. Noninvasive biomarkers represent valuable tools for monitoring longitudinal disease activity. We should understand them well, and optimizing how we evaluate CD lesions with SB involvement is critical to improving future outcomes.

\section{Conclusions}

We reviewed objective evaluation modalities for CD. As modalities have advanced, they have changed the assessment of $\mathrm{CD}$, with SB involvement becoming more important. Proper optimization is necessary in clinical practice. 
Table 1 Pros and Cons of each examination

\begin{tabular}{lll}
\hline & Pros & Cons \\
\hline CS & $\begin{array}{l}\text { Gold standard of mucosal healing } \\
\text { Histological evaluation } \\
\text { Endoscopic therapy }\end{array}$ & Limited small bowel assessment \\
& Detailed small bowel assessment & \\
BAE & Histological evaluation & Low accessibility \\
& Endoscopic therapy & High invasiveness \\
CE & Small bowel mucosal assessment & \\
& Low invasiveness & Retention of capsule \\
CTE & Evaluation for extraintestinal complications & Radiation exprosure \\
& Good accessibility & No validated score \\
MRE & High spatial resolution & Evaluation for extraintestinal complications \\
& No radiation exprosure & Low sensitivity for small bowel strictures \\
& Widely accepted for monitoring & Limited examination facilities \\
US & No invasiveness & Low sensitivity for small bowel strictures \\
& Possible for repeated assessment & No validated score
\end{tabular}

$C S$ ileocolonoscopy, $B A E$ balloon-assisted enteroscopy, $C E$ capsule endoscopy, $C T E$ computed tomography enteroscopy, MRE magnetic resonance enterography, US ultrasonography
Acknowledgements The part of the figure in the manuscript was provided by KYORIN Pharmaceutical Co.,Ltd.

Author contributions KTa drafted the manuscript; KT, YK, and TF collected evidence; KTs, MW, and KO critically revised the manuscript; and KTs and MW supervised the study. KTa and KO contributed equally to this study.

\section{Compliance with ethical standards}

Conflict of interest Employment/Leadership position/ Advisory role: Mitsubishi Tanabe Pharma Corporation, Takeda Pharmaceutical Company Limited (KTs).

Open Access This article is licensed under a Creative Commons Attribution 4.0 International License, which permits use, sharing, adaptation, distribution and reproduction in any medium or format, as long as you give appropriate credit to the original author(s) and the source, provide a link to the Creative Commons licence, and indicate if changes were made. The images or other third party material in this article are included in the article's Creative Commons licence, unless indicated otherwise in a credit line to the material. If material is not included in the article's Creative Commons licence and your intended use is not permitted by statutory regulation or exceeds the permitted use, you will need to obtain permission directly from the copyright holder. To view a copy of this licence, visit http://creativecommons. org/licenses/by/4.0/.

\section{References}

1. Schwartz DA, Loftus EV, Tremaine WJ, et al. The natural history of fistulizing Crohn's disease in Olmsted County, Minnesota. Gastroenterology. 2002;122:875-80.

2. Loftus EV. Clinical epidemiology of inflammatory bowel disease: incidence, prevalence, and environmental influences. Gastroenterology. 2004;126(6):1504-17.
3. Louis E, Collard A, Oger AF, et al. Behaviour of Crohn's disease according to the Vienna classification: changing pattern over the course of the disease. Gut. 2001;49:777-82.

4. Gower-Rousseau C, Sarter H, Savoye G, et al; International Programme to Develop New Indexes for Crohn's Disease (IPNIC) group. Validation of the inflammatory bowel disease disability index in a population-based cohort. Gut 2017;66:588-96

5. Siegel CA, Whitman CB, Spiegel BMR, et al. Development of an index to define overall disease severity in IBD. Gut. 2018;67:244-54.

6. Sandborn WJ, Hanauer S, Van Assche G, et al. Treating beyond symptoms with a view to improving patient outcomes in inflammatory bowel diseases. J Crohns Colitis. 2014;8:927-35.

7. Baert F, Moortgat L, Van Assche G, et al. Mucosal healing predicts sustained clinical remission in patients with early-stage Crohn's disease. Gastroenterology. 2010;138:463-8.

8. Peyrin-Biroulet L, Sandborn W, Sands BE, et al. Selecting Therapeutic Targets in Inflammatory Bowel Disease (STRIDE): determining therapeutic goals for treat-to-target. Am J Gastroenterol. 2015;9:1324-38.

9. Neurath MF, Travis SP. Mucosal healing in inflammatory bowel diseases: a systematic review. Gut. 2012;61:1619-35.

10. Ng SC, Tang W, Ching JY, et al. Incidence and phenotype of inflammatory bowel disease based on results from the Asiapacific Crohn's and colitis epidemiology study. Gastroenterology. 2013;145:158-65.

11. Maaser C, Sturm A, Vavricka SR, et al. ECCO-ESGAR Guideline for Diagnostic Assessment in IBD Part 1: Initial diagnosis, monitoring of known IBD, detection of complications. J Crohns Colitis. 2019;13:144-64.

12. Rutgeerts P, Vermeire S, Van Assche G. Mucosal healing in inflammatory bowel disease: impossible ideal or therapeutic target? Gut. 2007;56:453-5.

13. Froslie KF, Jahnsen J, Moum BA, et al. Mucosal healing in inflammatory bowel disease: results from a Norwegian population-based cohort. Gastroenterology. 2007;133:412-22. 
14. Colombel JF, Sandborn WJ, Reinisch W, et al. Infliximab, azathioprine, or combination therapy for Crohn's disease. N Engl J Med. 2010;362:1383-95.

15. Colombel JF, Rutgeerts P, Reinisch W, et al. Early mucosal healing with infliximab is associated with improved long-term clinical outcomes in ulcerative colitis. Gastroenterology. 2011;141:1194-201.

16. Dulai PS, Singh S, Jiang X, et al. The real-world effectiveness and safety of vedolizumab for moderate-severe Crohn's disease: results from the US VICTORY Consortium. Am J Gastroenterol. 2016;111:1147-55.

17. Ma C, Fedorak RN, Kaplan GG, et al. Clinical, endoscopic and radiographic outcomes with ustekinumab in medically-refractory Crohn's disease: real world experience from a multicentre cohort. Aliment Pharmacol Ther. 2017;45:1232-43.

18. Allez M, Lemann M, Bonnet J, et al. Long term outcome of patients with active Crohn's disease exhibiting extensive and deep ulcerations at colonoscopy. Am J Gastroenterol. 2002;97:947-53.

19. Bouguen G, Levesque BG, Pola S, et al. Endoscopic assessment and treating to target increase the likelihood of mucosal healing in patients with Crohn's disease. Clin Gastroenterol Hepatol. 2014;12:978-85.

20. Modigliani R, Mary JY, Simon JF, et al. Clinical biological and endoscopic picture of attacks of Crohn's disease Evolution on prednisolone. Gastroenterology. 1997;98:811-8.

21. Daperno M, D'Haens G, Van Assche G, et al. Development and validation of a new, simplified endoscopic activity score for Crohn's disease: the SES-CD. Gastrointest Endosc. 2004;60:505-12.

22. Iacucci M, Furfaro F, Matsumoto T, et al. Advanced endoscopic techniques in the assessment of inflammatory bowel disease: new technology, new era. Gut. 2018. https://doi.org/10.1136/ gutjnl-2017-315235.

23. Vuitton L, Marteau P, Sandborn WJ, et al. IOIBD technical review on endoscopic indices for Crohn's disease clinical trials. Gut. 2016;65:1447-555.

24. Cosnes J, Gower-Rousseau C, Seksik P, et al. Epidemiology and natural history of inflammatory bowel diseases. Gastroenterology. 2011;140:1785-94.

25. Tharian B, George N, Navaneethan U. Endoscopy in the diagnosis and management of complications of inflammatory bowel disease. Inflamm Bowel Dis. 2016;22:1184-97.

26. Navaneethan U, Lourdusamy V, Njei B, et al. Endoscopic balloon dilation in the management of strictures in Crohn's disease: a systematic review and meta-analysis of non-randomized trials. Surg Endosc. 2016;30:5434-43.

27. Hassan C, Zullo A, De Francesco V, et al. Systematic review: endoscopic dilatation in Crohn's disease. Aliment Pharmacol Ther. 2007;26:1457-64.

28. Rutgeerts P, Geboes K, Vantrappen G, et al. Natural history of recurrent Crohn's disease at the ileocolonic anastomosis after curative surgery. Gut. 1984;25:665-72.

29. Olaison G, Smedh K, Sjodahl R. Natural course of Crohn's disease after ileocolic resection: endoscopically visualised ileal ulcers preceding symptoms. Gut. 1992;33:331-5.

30. Rutgeerts P, Geboes K, Vantrappen G, et al. Predictability of the postoperative course of Crohn's disease. Gastroenterology. 1990;99:956-63.

31. De Cruz P, Kamm MA, Hamilton AL, et al. Crohn's disease management after intestinal resection: a randomised trial. Lancet. 2015;385:1406-17.

32. Regueiro M, Velayos F, Greer JB, et al. American gastroenterological association institute technical review on the management of Crohn's disease after surgical resection. Gastroenterology. 2017;152(277-95):e3.
33. Samuel S, Bruining DH, Loftus EV, et al. Endoscopic skipping of the distal terminal ileum in Crohn's disease can lead to negative results from ileocolonoscopy. Clin Gastroenterol Hepatol. 2012;10:1253-9.

34. Yamamoto H, Kita H, Sunada K, et al. Clinical outcomes of double-balloon endoscopy for the diagnosis and treatment of small-intestinal diseases. Clin Gastroenterol Hepatol. 2004;2:1010-6.

35. Ohtsuka K, Kashida H, Kodama K, et al. Diagnosis and treatment of small bowel diseases with a newly developed single balloon endoscope. Dig Endosc. 2008;20:134-7.

36. Fukumoto A, Tanaka S, Yamamoto $\mathrm{H}$, et al. Diagnosis and treatment of small-bowel stricture by double balloon endoscopy. Gastrointest Endosc. 2007;66:S108-S112112.

37. Dulai PS, Levesque BG, Feagan BG, D'Haens G, Sandborn WJ. Assessment of mucosal healing in inflammatory bowel disease: review. Gastrointest Endosc. 2015;82:246-55.

38. Fan R, Zhong J, Wang Zt, Li SY, Zhou J, Tang YH. Evaluation of "top-down" treatment of early Crohn's disease by double balloon enteroscopy. World J Gastroenterol. 2014;20:14479-87.

39. Takenaka K, Ohtsuka K, Kitazume Y, et al. Comparison of magnetic resonance and balloon enteroscopic examination of the small intestine in patients with Crohn's disease. Gastroenterology. 2014;147:334-42.

40. Takenaka K, Ohtsuka K, Kitazume Y, et al. Correlation of the endoscopic and magnetic resonance scoring systems in the deep small intestine in Crohn's disease. Inflamm Bowel Dis. 2015;21:1832-8.

41. Takenaka K, Ohtsuka K, Kitazume Y, et al. Utility of magnetic resonance enterography for small bowel endoscopic healing in patients with Crohn's disease. Am J Gastroenterol. 2018;113:283-94.

42. Hirai F, Andoh A, Ueno F, et al. Efficacy of endoscopic balloon dilation for small bowel strictures in patients with Crohn's disease: a nationwide, multi-centre, open-label prospective cohort study. J Crohns Colitis. 2018;12:394-401.

43. Takabayashi K, Hosoe N, Miyanaga R, et al. Clinical utility of novel ultrathin single-balloon enteroscopy: a feasibility study. Endoscopy. 2019;51:468-71.

44. Sunada K, Shinozaki S, Nagayama M, et al. Long-term outcomes in patients with small intestinal strictures secondary to Crohn's disease after double-balloon endoscopy-assisted balloon dilation. Inflamm Bowel Dis. 2016;22:380-6.

45. Hirai F. Current status of endoscopic balloon dilation for Crohn's disease. Intest Res. 2017;15:166-73.

46. Odagiri H, Matsui H, Fushimi K, et al. Factors associated with perforation related to diagnostic balloon-assisted enteroscopy: analysis of a national inpatient database in Japan. Endoscopy. 2015;47:143-6.

47. Arulanandan A, Dulai PS, Singh S, et al. Systematic review: Safety of balloon assisted enteroscopy in Crohn's disease. World J Gastroenterol. 2016;22:8999-9011.

48. Moschler O, May A, Muller MK, Ell C. Complications in and performance of double-balloon enteroscopy (DBE): results from a large prospective DBE database in Germany. Endoscopy. 2011;43:484-9.

49. Iddan G, Meron G, Glukhovsky A, Swain P. Wireless capsule endoscopy. Nature. 2000;405:417.

50. Fireman Z, Mahajna E, Broide E, et al. Diagnosing small bowel Crohn's disease with wireless capsule endoscopy. Gut. 2003;52:390-2.

51. Girelli CM, Porta P, Malacrida V, et al. Clinical outcome of patients examined by capsule endoscopy for suspected small bowel Crohn's disease. Dig Liver Dis. 2007;39:148-54. 
52. Maiden L, Thjodleifsson B, Theodors A, et al. A quantitative analysis of NSAID-induced small bowel pathology by capsule enteroscopy. Gastroenterology. 2005;128:1172-8.

53. Tukey M, Pleskow D, Legnani P, et al. The utility of capsule endoscopy in patients with suspected Crohn's disease. Am J Gastroenterol. 2009;104:2734-9.

54. Kopylov U, Nemeth A, Koulaouzidis A, et al. Small bowel capsule endoscopy in the management of established Crohn's disease: clinical impact, safety, and correlation with inflammatory biomarkers. Inflamm Bowel Dis. 2015;21:93-100.

55. Long MD, Barnes E, Isaacs K, et al. Impact of capsule endoscopy on management of inflammatory bowel disease: a single tertiary care center experience. Inflamm Bowel Dis. 2011;17:1855-62.

56. Greener T, Klang E, Yablecovitch D, et al. The impact of magnetic resonance enterography and capsule endoscopy on the reclassification of disease in patients with known Crohn's disease: a prospective Israeli IBD Research Nucleus (IIRN) study. J Crohns Colitis. 2016;10:525-31.

57. Triester SL, Leighton JA, Leontiadis GI, et al. A meta-analysis of the yield of capsule endoscopy compared to other diagnostic modalities in patients with non-stricturing small bowel Crohn's disease. Am J Gastroenterol. 2006;101:954-64.

58. Kopylov U, Yung DE, Engel T, et al. Diagnostic yield of capsule endoscopy versus magnetic resonance enterography and small bowel contrast ultrasound in the evaluation of small bowel Crohn's disease: systematic review and meta-analysis. Dig Liver Dis. 2017;49:854-63.

59. Ben-Horin S, Lahat A, Amitai MM, et al. Assessment of small bowel mucosal healing by video capsule endoscopy for the prediction of short-term and long-term risk of Crohn's disease flare: a prospective cohort study. Lancet Gastroenterol Hepatol. 2019;4:519-28.

60. Cheifetz AS, Kornbluth AA, Legnani P, et al. The risk of retention of the capsule endoscope in patients with known or suspected Crohn's disease. Am J Gastroenterol. 2006;101:2218-22.

61. Shergill AK, Lightdale JR, Bruining DH, et al. The role of endoscopy in inflammatory bowel disease. Gastrointest Endosc. 2015;81:1101-21.e1-13.

62. Rozendorn N, Klang E, Lahat A, et al. Prediction of patency capsule retention in known Crohn's disease patients by using magnetic resonance imaging. Gastrointest Endosc. 2016;83:182-7.

63. Panes J, Bouhnik Y, Reinisch W, et al. Imaging techniques for assessment of inflammatory bowel disease: joint ECCO and ESGAR evidence-based consensus guidelines. J Crohns Colitis. 2013;7:556-85.

64. Fernandes SR, Rodrigues RV, Bernardo S, et al. Transmural healing is associated with improved long-term outcomes of patients with Crohn's disease. Inflamm Bowel Dis. 2017;23:1403-9.

65. Ordas I, Rimola J, Rodriguez S, et al. Accuracy of magnetic resonance enterography in assessing response to therapy and mucosal healing in patients with Crohn's disease. Gastroenterology. 2014;146:374-82.

66. Plumb AA, Menys A, Russo E, et al. Magnetic resonance imaging-quantified small bowel motility is a sensitive marker of response to medical therapy in Crohn's disease. Aliment Pharmacol Ther. 2015;42:343-55.

67. Coimbra AJ, Rimola J, O’Byrne S, et al. Magnetic resonance enterography is feasible and reliable in multicenter clinical trials in patients with Crohn's disease, and may help select subjects with active inflammation. Aliment Pharmacol Ther. 2016;43:61-72.
68. Taylor SA, Avni F, Cronin CG, et al. The first joint ESGAR/ ESPR consensus statement on the technical performance of cross-sectional small bowel and colonic imaging. Eur Radiol. 2017;27:2570-82.

69. Grand DJ, Guglielmo FF, Al-Hawary MM. MR enterography in Crohn's disease: current consensus on optimal imaging technique and future advances from the SAR Crohn's diseasefocused panel. Abdom Imaging. 2015;40:953-64.

70. Quencer KB, Nimkin K, Mino-Kenudson M, Gee MS. Detecting active inflammation and fibrosis in pediatric Crohn's disease: prospective evaluation of MR-E and CT-E. Abdom Imaging. 2013;38:705-13.

71. Oussalah A, Laurent V, Bruot O, et al. Diffusion-weighted magnetic resonance without bowel preparation for detecting colonic inflammation in inflammatory bowel disease. Gut. 2010;59:1056-65.

72. Menys A, Helbren E, Makanyanga J, et al. Small bowel strictures in Crohn's disease: a quantitative investigation of intestinal motility using MR enterography. Neurogastroenterol Motil. 2013;25:967-e775.

73. Rimola J, Rodriguez S, Garcia-Bosch O, et al. Magnetic resonance for assessment of disease activity and severity in ileocolonic Crohn's disease. Gut. 2009;58:1113-20.

74. Steward MJ, Punwani S, Proctor I, et al. Non-perforating small bowel Crohn's disease assessed by MRI enterography: derivation and histopathological validation of an MR-based activity index. Eur J Radiol. 2012;81:2080-8.

75. Hordonneau C, Buisson A, Scanzi J, et al. Diffusion-weighted magnetic resonance imaging in ileocolonic Crohn's disease: validation of quantitative index of activity. Am J Gastroenterol. 2014;109:89-988.

76. Makanyanga JC, Pendse D, Dikaios N, et al. Evaluation of Crohn's disease activity: initial validation of a magnetic resonance enterography global score (MEGS) against faecal calprotectin. Eur Radiol. 2014;24:277-87.

77. Ordás I, Rimola J, Alfaro I, et al. Development and validation of a simplified magnetic resonance index of activity for Crohn's disease. Gastroenterology. 2019;157:432-9.

78. Kitazume Y, Fujioka T, Takenaka K, et al. Crohn disease: a 5-point MR enterocolonography classification using enteroscopic findings. AJR Am J Roentgenol. 2019;212:67-766.

79. Pariente B, Mary JY, Danese S, et al. Development of the Lemann index to assess digestive tract damage in patients with Crohn's disease. Gastroenterology. 2015;148:52-63.

80. Fujii T, Naganuma M, Kitazume Y, et al. Advancing magnetic resonance imaging in Crohn's disease. Digestion. 2014;89:24-30.

81. Qiu Y, Mao R, Chen BL, et al. Systematic review with metaanalysis: magnetic resonance enterography vs. computed tomography enterography for evaluating disease activity in small bowel Crohn's disease. Aliment Pharmacol Ther. 2014;40:134-46.

82. Takenaka K, Ohtsuka K, Kitazume Y, et al. Magnetic resonance evaluation for small bowel strictures in Crohn's disease: comparison with balloon enteroscopy. J Gastroenterol. 2017:52:879-88.

83. Desmond AN, O'Regan K, Curran C, et al. Crohn's disease: factors associated with exposure to high levels of diagnostic radiation. Gut. 2008;57:1524-9.

84. Bruining DH, Loftus EV Jr, Ehman EC, et al. Computed tomography enterography detects intestinal wall changes and effects of treatment in patients with Crohn's disease. Clin Gastroenterol Hepatol. 2011;9:679-83.

85. Arai T, Takeuchi K, Miyamura M, et al. Level of fecal calprotectin correlates with severity of small bowel Crohn's disease, measured by balloon-assisted enteroscopy and computed 
tomography enterography. Clin Gastroenterol Hepatol. 2017;15:56-62.

86. Amitai MM, Ben-Horin S, Eliakim R, Kopylov U. Magnetic resonance enterography in Crohn's disease: a guide to common imaging manifestations for the IBD physician. J Crohns Colitis. 2013;7:603-15.

87. Minordi LM, Scaldaferri F, Larosa L, et al. Comparison between clinical and radiological evaluation before and after medical therapy in patients with Crohn's disease: new prospective roles of CT enterography. Radiol Med. 2015;120:449-57.

88. Chatu S, Poullis A, Holmes R, et al. Temporal trends in imaging and associated radiation exposure in inflammatory bowel disease. Int J Clin Pract. 2013;67:1057-65.

89. Calabrese E, Maaser C, Zorzi F, et al. Bowel ultrasonography in the management of Crohn's disease. A review with recommendations of an international panel of experts. Inflamm Bowel Dis. 2016;22:1168-83.

90. Moreno N, Ripollés T, Paredes JM, et al. Usefulness of abdominal ultrasonography in the analysis of endoscopic activity in patients with Crohn's disease: changes following treatment with immunomodulators and/or anti-TNF antibodies. J Crohns Colitis. 2014;8:1079-87.

91. Zorzi F, Stasi E, Bevivino G, et al. A sonographic lesion index for Crohn's disease helps monitor changes in transmural bowel damage during therapy. Clin Gastroenterol Hepatol. 2014;12:2071-7.

92. Civitelli F, Nuti F, Oliva S, et al. Looking beyond mucosal healing: effect of biologic therapy on transmural healing in pediatric Crohn's disease. Inflamm Bowel Dis. 2016;22:2418-24.

93. Orlando S, Fraquelli M, Coletta M, et al. Ultrasound elasticity imaging predicts therapeutic outcomes of patients with Crohn's disease treated with anti-tumour necrosis factor antibodies. J Crohns Colitis. 2018;12:63-70.

94. Deepak P, Fletcher JG, Fidler JL, et al. Radiological response is associated with better long-term outcomes and is a potential treatment target in patients with small bowel Crohn's disease. Am J Gastroenterol. 2016;111:997-1006.

95. Ripollés T, Paredes JM, Martínez-Pérez MJ, et al. Ultrasonographic changes at 12 weeks of anti-TNF drugs predict 1-year sonographic response and clinical outcome in Crohn's disease: a multicenter study. Inflamm Bowel Dis. 2016;22:2465-73.

96. Dillman JR, Smith EA, Sanchez R, et al. Prospective cohort study of ultrasound-ultrasound and ultrasound-MR enterography agreement in the evaluation of pediatric small bowel Crohn disease. Pediatr Radiol. 2016;46:490-7.

97. Castiglione F, Testa A, Rea M, et al. Transmural healing evaluated by bowel sonography in patients with Crohn's disease on maintenance treatment with biologics. Inflamm Bowel Dis. 2013;19:1928-34.

98. Kucharzik T, Wittig BM, Helwig U, et al. Use of intestinal ultrasound to monitor Crohn's disease activity. Clin Gastroenterol Hepatol. 2017;15:535-42.

99. Panes J, Bouzas R, Chaparro M, et al. Systematic review: the use of ultrasonography, computed tomography and magnetic resonance imaging for the diagnosis, assessment of activity and abdominal complications of Crohn's disease. Aliment Pharmacol Ther. 2011;34:125-45.
100. Calabrese E, Kucharzik T, Maaser C, et al. Real-time interobserver agreement in bowel ultrasonography for diagnostic assessment in patients with Crohn's disease: an international multicenter study. Inflamm Bowel Dis. 2018;16(24):2001-6.

101. Knieling F, Neufert C, Hartmann A, et al. Multispectral optoacoustic tomography for assessment of Crohn's disease activity. N Engl J Med. 2017;376:1292-4.

102. Sands BE. Biomarkers of inflammation in inflammatory bowel disease. Gastroenterology. 2015;149:1275-85.

103. Kiss LS, Papp M, Lovasz BD, et al. High sensitivity C-reactive protein for identification of disease phenotype, active disease, and clinical relapses in Crohn's disease: a marker for patient classification? Inflamm Bowel Dis. 2012;18:1647-54.

104. Jones J, Loftus EV Jr, Panaccione R, et al. Relationships between disease activity and serum and fecal biomarkers in patients with Crohn's disease. Clin Gastroenterol Hepatol. 2008;6:1218-24.

105. Vermeire S, Van Assche G, Rutgeerts P. C-reactive protein as a marker for inflammatory bowel disease. Inflamm Bowel Dis. 2004;10:661-5.

106. Schoepfer AM, Beglinger C, Straumann A, et al. Fecal calprotectin correlates more closely with the Simple Endoscopic Score for Crohn's disease (SES-CD) than CRP, blood leukocytes, and the CDAI. Am J Gastroenterol. 2010;105:162-9.

107. Lobaton T, Lopez-Garcia A, Rodriguez-Moranta F, et al. A new rapid test for fecal calprotectin predicts endoscopic remission and postoperative recurrence in Crohn's disease. J Crohns Colitis. 2013;7:e641-651.

108. Iwamoto F, Matsuoka K, Motobayashi M, et al. Prediction of disease activity of Crohn's disease through fecal calprotectin evaluated by balloon-assisted endoscopy. J Gastroenterol Hepatol. 2018;33:1984-9.

109. Inokuchi T, Kato J, Hiraoka S, et al. Fecal immunochemical test versus fecal calprotectin for prediction of mucosal healing in Crohn's disease. Inflamm Bowel Dis. 2016;22:1078-85.

110. Colombel JF, Panaccione R, Bossuyt P, et al. Effect of tight control management on Crohn's disease (CALM): a multicentre, randomised, controlled phase 3 trial. Lancet. 2018;390:2779-89.

111. Kopylov U, Yablecovitch D, Lahat A, et al. Detection of small bowel mucosal healing and deep remission in patients with known small bowel Crohn's disease using biomarkers, capsule endoscopy, and imaging. Am J Gastroenterol. 2015;110:1316-23.

112. Takenaka K, Fujii T, Suzuki K, et al. Small bowel healing detected by endoscopy in patients with Crohn's disease after treatment with antibodies against tumor necrosis factor. Clin Gastroenterol Hepatol. 2019

113. Lazarev M, Huang C, Bitton A, et al. Relationship between proximal Crohn's disease location and disease behavior and surgery: a cross-sectional study of the IBD Genetics Consortium. Am J Gastroenterol. 2013;108:106-12.

Publisher's Note Springer Nature remains neutral with regard to jurisdictional claims in published maps and institutional affiliations. 